\title{
STUDENTS GENDER AS A MODERATING FACTOR OF CORRELATION BETWEEN LINGUISTIC CAPITAL AND ACADEMIC OUTCOMES
}

\author{
KAMIL BŁASZCZYŃSKI \\ Faculty of Psychology, University of Wrocław \\ Ul. Dawida 1, Wrocław, Poland \\ E-mail address: kamil.b.1988@wp.pl \\ ORCID: https://orcid.org/0000-0003-4896-8371
}

\begin{abstract}
Aim: The aim of this paper is to verify the impact of gender on correlations between native language competences and academic activity of master grade students of social sciences in Poland. Results are discussed with other international findings.

Methods: Gathering of the data was via an auditorial survey. Data was collected from 235 students (163 female, 73 male) at the Faculty of Social Sciences at one of the Polish national universities. It was analysed using T-Students test and Linear Regression models.

Results: T-Students test results indicate that female students have significantly higher educational outcomes and study results scores than male students. Regression analysis reveals that gender as a moderating factor of linguistic capital is a significant predictor in regard to students education outcomes and study results. The main part of linguistic capital significantly moderated by gender is language experience.

Conclusions: Female students have equal linguistic capital and language experiences to male students, however they are more capable of using that capital to their benefit in the context of academic education. Implications of the study and future recommendations are advised.
\end{abstract}

Key words: gender, academic education, university studies, gender differences

\section{INTRODUCTION}

$\mathrm{B}$ ecause of the structural, cultural and social factors men and women are bound by different social norms which limit their activity in certain environments (Gormley, 2015). One such environment is the university and the structure of higher education. In the historical perspective, studies regarding educational differences between male and female students were first inspired by the changes in social structures which were strengthened by liberal feminist movements in Europe and the USA (Schiebinger, 2000). The role of those studies was, firstly, to verify various myths or misconceptions regarding the 
nature of the sexes, and secondly, to attempt at reconstructing of the cultural dynamics of creations of gender differences. Nowadays it is obvious to state that differences between men and women in their educational behaviour are a mix of some biological and mostly socio-cultural factors that shape one's consciousness at the very early life stages (Veldea, Tyrowicz, \& Siwinska, 2015). Nevertheless, due to the sheer cultural complexity of society, as well as the fact that cultural, social and technological developments change the environmental qualities that shape gender roles and the fact that results are not equally representative in reference to cultural circles, social groups or stages of human psychological development, there is a lot to explore in detail. Thus the general aim of this study is to establish if the gender differences in educational outcomes are visible in the context of the Polish university educationand to explore how the diagnosed conditions connect with scientific findings from other countries and cultural circles.

\section{GENDER AND HIGHER EDUCATION}

There are numerous studies concerning the role of gender in academic achievements (see: Fin, \& Ishak, 2012; Oladokun, \& Oladokun, 2017; Raheem, 2017; Ayodele, 2019). Meta-analysis conducted by Severiens and Ten Dam (1994) on 26 empirical studies using Kolb's Learning Inventory confirmed lack of significant differences in educational outcomes. However, male students preferred an abstract conceptualisation mode of learning more than females. Furthermore, male students were more interested in qualifications they were to gain, while female students learnt just for the sake of learning. Male students also had a deeper understanding of learning, while female students were more surface-oriented and they often had a reproductive attitude. Lastly, effective sizes for the noted differences in learning understanding were small.

A study conducted by Jacob (2002) on NELS participants ( $\mathrm{n}=10925 \mathrm{stu}-$ dents) regarding the comparison of non-cognitive skills between male and female students in higher education proved that female scores in higher education are higher than males and, if there are any gender differences, they have mostly a non-cognitive feature. Therefore, this study implies that there are no significant biological gender differences when it comes to the education capacity.

Research conducted by Saunder, Davis, Williams and Williams (2004) on African American students in the Midwest ( $\mathrm{n}=243 ; 107$ males and 136 female students) regarding self-perception and academic outcomes proved that female students had higher grades and stronger motivation towards educational attainment than males. A limitation of this study is that the results were obtained on a sample from a single school and confirmed the cultural and social problems of an African American ethnic group, therefore, they cannot be extrapolated on other Western cultures. 
A study conducted by Dayioğlu and Türüt-Aşik (2007) explored the gender differences in education outcomes at a public university in Turkey $(n=10343)$ and concluded that female students outperform male students during university studies. Female students began university with lower scores and with each year they performed better and better in comparison with their male peers. Limitations of this study are in the probe selection that consisted only of students of one university, which gives no possibility to form general conclusions in regard to the Turkish academic education or academic education at all.

An empirical study conducted by Erten (2009) confirmed significant differences between male and female students in terms of their academic outcomes, pointing female students as being more long-term metacognitive efficient. The result was explained by different role artefacts for both genders, which moderated motivation and perception of their own profession. A limitation of this study is in the probe size $(n=122)$, which gives no field for general assumptions.

A study conducted by López-Pérez, Pérez-López, \& Rodríguez-Ariza (2011) on students of the University of Granada $(n=1431)$ proved that gender significantly yet weakly influenced the education outcomes in blended learning method, therefore the single impact of gender was limited and no significant differences were observed. The study performed by the team Kim, Kwon and Cho (2011) was focused on the gender differences in social presence and learning satisfaction and discovered that gender was not a significant factor.

Research conducted by Wan Chik et al. (2012) on Malayan students ( $\mathrm{n}=147$ : 28 male and 119 female students) in regard to gender differences in academic performances proved that males had significantly lower grades than females and gender was the only significant predictor of one's performances. A limitation of this study is the probe size, statistically unequal groups of comparison and limited selection of students in the study (one university), which gives no possibility for general conclusions and gives field of assumption that the compared scores between groups were influenced by the larger female sample, thus limiting the results and conclusion only to the tested group.

A study conducted by Martinho, Albergaria-Almeida and Dias (2015) on Portuguese students ( $n=67 ; 26$ male and 41 female) regarding gender influence on the levels of cooperation and competitiveness in higher education science proved statistically significant. Female students were more cooperation orientated, males, on the other hand, were more competitive. A limitation of the study is the probe size which is unrepresentative. Also the research procedure, which measured the level of cooperation and competitiveness of the students with the number of questions asked by students in specific situations, is a limitation. Moreover, the authors state that they assumed that the cognitive capabilities of all participants were equally high, clearly stating that further, more detail studies are required.

A study conducted at the University of Zambia by Ezeala and Siyanga (2015), which analysed the impact of gender on the study skills of undergradu- 
ate pharmacy students $(\mathrm{n}=67)$, proved no significant differences. Limitations of this study are the probe size (unrepresentative sample) and the group homogeneity (only pharmacy).

A study conducted on Spanish students ( $\mathrm{n}=168)$ by Núñez-Peñaab, SuárezPellicionic and Bono (2016) regarding the gender differences in the levels of test anxiety and academic achievements proved that although female students had higher levels in all anxiety fields than males, it did not influence significantly their academic achievements in comparison to male students. Limitation of this study is in the significant disproportion between the compared groups of gender (135 female and 33 male students). Thus all conducted T-test statistics presented in the cited paper are influenced by the group disproportion and may prove impossible to replicate in equally large groups.

A study conducted by team Thiele, Pope, Singleton and Stanistreet (2016) that focused on the prediction of academic performance of students at a medical university discovered that female students generally had slightly, yet significantly higher grades than males and that gender was a significant predictor of education outcomes on different levels of medical education. However, this study was only limited to the medical field of education, thus further extrapolation on other fields of sciences is not possible.

A study conducted in South Africa by Subbaye and Vithal (2017) focused on gender differences in the academic promotion and pointed out that both genders had equal promotion success with no significant statistical differences.

A study conducted by Bekleyen (2017) on Turkish university students $(n=313$ : 144 male and 169 female students) regarding differentiation of academic procrastination proved that male students had a significantly higher level of procrastination than female students. A limitation of this study is the fact that it does not include academic outcomes of the diagnosed groups.

A study conducted by Almasi, Zhu and Machumu (2018) on students of a Tanzanian university $(n=353)$ proved that there was no gender impact on teaching, cognitive and social presence outcomes in regard to blended learning. A limitation of this study is the fact that it was not a longitudinal study, thus it is not clear if the lack of gender impact changes in groups over time.

On the basis of the presented studies, it is possible to conclude that gender and education outcomes in higher education cannot be easily connected and reduced to a cause-effect model. The quality of the connection between the aforementioned variables seems to vary depending strongly on social and cultural factors. Many of the cited studies point out that when gender differences are visible in education outcomes, they describe females as better students; nevertheless, it should be emphasised that in all studies authors do not offer any generalisation and advice caution in formulating any obvious statements. Thus the proposed study seems valuable as: 1) it aims at predicting the phenomenon of gender and education outcomes in specific-academic-context; 2 ) it gives new different social and cultural context to the current data, thus providing further arguments in the ongoing debate. 


\section{GENDER AND LANGUAGE COMPETENCIES}

The relation between gender and language competencies has already been object of scientific consideration. A study conducted on undergraduate students of a Western university ( $\mathrm{n}=127 ; 64$ male and 63 female students) by Mulac, Giles, Bradac and Palomares (2013) regarding general language effect pointed out significant differences in the language usage, suggesting that noted differences are a direct consequence of associated gender schemata and stereotypes of communication.

A study conducted on Malaysian students $(n=60)$ by Rafek et al. (2014) regarding the role of gender and apprehension in second language learning proved that gender has a significant impact on the behaviour of students. The authors state that apprehension and, in consequence, low confidence to fulfil the expectations result in strong insecurity in female and male students and, hence, lowers their language activity. However, the cited study does not clearly point out any sharp differences between the students of different genders, stating generally that anxiety lowers education performances of both sexes with no clear distinction where are the crucial and measureable differences in behaviour strategies.

A meta-analysis of Davis and Reynolds (2018) on the impact of gendered language on the educational gender gap $(n=76000)$ showed that the more one's language is gendered, the bigger gaps in the educational attainment are noted. In other words, if there is easily distinguishable feminine and masculine grammatical gender in a language, it may suggest that the educational system based on that language will diverse learning outcomes of students on the basis of their gender.

On the basis of the cited studies, it is possible to conclude that male and female students use different language schemata and use different language stereotypes. Those schemes and stereotypes are probably the effects of gendered grammar structure which is a part of one's language assimilated during primary and secondary socialisation. As Polish language is strongly gendered, there is convincing evidence to assume in this study that noted education outcomes between female and male students may be indirect results of language capital. Due to lack of precise studies regarding this topic in Poland, the proposed study is one of few which may result in valuable data and may be a good starting point for further exploration regarding comparable studies conducted in different cultures and societies.

\section{CULTURAL CAPITAL AND LEARNING OUTCOMES}

In a large meta-analysis on various age groups in various countries conducted by Tramonte and Willms (2010) ( $\mathrm{n}=159$ 095), a significant impact of gender on education outcomes in the form of the gender gap has been indicated. Moreover, gender gaps differ in their size in different countries, but there is a universal tendency suggesting higher scores for females. 
In a study conducted by Nishioka and Durrani (2019) on Malawi students (aged 15-24), it has been pointed out that linguistic capital (part of one's cultural capital) has a significant impact on the education outcomes and it has been suggested that female students generally have higher education attainments than males. A limitation of this study is the cultural homogeneity of the diagnosed pupils, which gives no possibility to extrapolate those results on other culturally different countries.

From the cited studies, it is possible to state that gender, cultural capital and education outcomes may be strictly connected, although the quality of the connection may differ according to the cultural and social background of the diagnosed group. The only empirical study which focused on all of the aforementioned variables and was conducted on Malawi students suggests that linguistic capital is important (confirming assumptions stated herein, part on Gender and Language Competencies) in education outcomes and that female students were ones to use it with more efficiency, which is compatible with findings regarding gender differences in education in general (herein, part on Gender and Higher Education). The proposed study could prove valuable because it focuses on a very precise problem, diagnosed insofar only in the Asiatic cultural context, and includes findings gathered in different cultural context and conditions. Such data may prove valuable in terms of enriching the ongoing debate and giving proof for formulating further, more general conclusions.

\section{HYPOTHESIS}

From the conducted literature review, it is possible to state that differences between male and female students in their language and education outcomes are very difficult to reduce to any clear and obvious statements. Any notable differences have strong social and cultural backgrounds and those can be moderated by linguistic, social, economic and cultural structures in which the students are living. However, there are visible tendencies that females indeed outperform their male counterparts in education outcomes. This can be explained by the study conducted by Severiens and Ten Dam (1994), which suggests that female students have a stronger tendency to fulfil structural expectations of the institution in which they are learning. This also has a strong backing in the study by Martinho, Albergaria-Almeida and Dias (2015), who suggest that female students are more orientated towards cooperation. Therefore, it seems that female students are more amenable to education structures, which makes them better students, thus giving them higher chances for better scores. Also, if we take into account a study conducted by Davis and Reynolds (2018), there is strong evidence to assume that in Polish cultural conditions (the Polish language is strongly gendered). gender will be a significant factor in moderating the role of linguistic capital in the education outcomes at Polish universities. 


\section{METHOD}

The theoretical background for the purposes of developing the research tools is based on the theory of social reproduction, cultural capital and linguistic capital by Bourdieu $(1973,1986 a, 1986 b, 1991)$ and the theory of reproduction in education of Bourdieu and Passeron (1977). For the purposes of this paper, the main conclusions from the presented workscan be summarised in the form of the following assumptions: 1) each student has a cultural capital which is a summary of his or her social and cultural backgrounds; 2 ) one of the elements of cultural capital is language; 3) language is a skill which is shaped by one's social and cultural experiences and serves both communication and decoding of symbolic meanings that fill the social sphere; 4) the better the skills in decoding of symbolic meanings in social spheres, the more symbolic power one gains, along with wider possibilities to achieve one's aims; 5) all social and cultural experiences are cumulative and may be strengthened by the quality and quantity of one's social and cultural activity; 6) all education structures have symbolic fields that are filled with symbolic meanings; 7) university education structure is filled with symbolic meaning in the form of scientific knowledge and logic of thinking which require high linguistic capital to be attained; and 8) the higher one's linguistic capital is, the better will be one's educational outcomes in the university education structure.

\section{PROBE AND PROCEDURE}

In the study participated 235 students of master degree studies, 163 female and 72 male students, all of whom were in the same age (female: Mdn=23, $\mathrm{SD}=0.912$, male: $\mathrm{Mdn}=23, \mathrm{SD}=1.19$ ). Students were from a Faculty of Social Sciences of one of the Polish national university. Data was collected in 2017 via an auditorial survey during the academic year at one of the students' courses. The survey was composed of 5 blocks of diagnostic data: 1 ) study results (5 items: 7-point scale); 2) scientific activity (5 items: 6 point scale); 3) writing activity (7 items: 6-point scale); 4) reading activity (8-items: 6-point scale); and 5) language experiences (22 items: 6-point scale $)^{1}$. The scores from each item were presented in the form of standardised z-scores for the purpose of further analysis. Reliability analysis for the research tool revealed Cronbach's alpha score $a=0.752$, therefore the used questionnaire was acceptably reliable.

Blocks 1 and 2 composed the students total academic education outcome meta-category. Due to the fact that both blocks were presented on different scales ( 7 and 6 point scales), the final scores of the meta-category were achieved by summing up raw scores for each block and then converting into raw z-scores. Converted z-scores were then converted into 10-point STEN scores. Next, converted STEN scores were summed up and divided by the number

1 The difference between the scales was due to authors decision to have study results block (7-point scale) more precise and sensitive than other blocks (6-point scale). For the purpose of analysis and conversion in $\mathrm{Z} Z$-scores, the difference in points of scale has been nullified. 
Journal of Education Culture and Society No. 1_2019

of blocks. Finally, achieved mean scores were converted for the second time into standardised z-scores, representing education-outcomes meta-category final score. Blocks from 3-5 and language test results composed the students linguistic capital. The score of this meta-category was calculated by summing up raw scores from single data blocks. The final result was converted into standardised z-scores. It was assumed that all items that were part of general meta-categories had the same statistical weight (for the detailed structure of the block see: Table 1.). Statistical data were analysed with Jamovi 0.9.5.16 open source programme.

Table 1.

Data block structure - Linguistic capital and education outcomes.

\begin{tabular}{|c|c|c|c|}
\hline $\begin{array}{l}\text { Meta- } \\
\text { category }\end{array}$ & Data block & Indicators/Items & $\begin{array}{l}\text { Type of } \\
\text { measure/scale }\end{array}$ \\
\hline \multirow[t]{26}{*}{$\begin{array}{l}\text { Linguistic } \\
\text { capital }\end{array}$} & $\begin{array}{l}\text { Writing } \\
\text { Activity }\end{array}$ & Blogs & Quantity/ordinal \\
\hline & & Discussion forums & Quantity/ordinal \\
\hline & & Popular science articles & Quantity/ordinal \\
\hline & & Press articles & Quantity/ordinal \\
\hline & & Books & Quantity/ordinal \\
\hline & & Diary & Duration/ordinal \\
\hline & & Poetry writing & Duration/ordinal \\
\hline & & Writing lyrics for music & Duration/ordinal \\
\hline & $\begin{array}{l}\text { Reading } \\
\text { activity }\end{array}$ & Blogs & Quantity/ordinal \\
\hline & & Discussion forums & Quantity/ordinal \\
\hline & & Popular science articles & Quantity/ordinal \\
\hline & & Press articles & Quantity/ordinal \\
\hline & & Books & Quantity/ordinal \\
\hline & & Scientific books & Quantity/ordinal \\
\hline & & Extracurricular scientific books & Quantity/ordinal \\
\hline & & Poetry reading & Quantity/ordinal \\
\hline & $\begin{array}{l}\text { Language } \\
\text { experiences }\end{array}$ & Literature association membership & Duration/ordinal \\
\hline & & Games & Duration/ordinal \\
\hline & & Team sports & Duration/ordinal \\
\hline & & Programming & Duration/ordinal \\
\hline & & Audio-visual content creation & Duration/ordinal \\
\hline & & Audio-visual content watching & Duration/ordinal \\
\hline & & Video conference - creation & Duration/ordinal \\
\hline & & Video conference - watching & Duration/ordinal \\
\hline & & Participation in literature contests & Duration/ordinal \\
\hline & & Participation in various workshops & Duration/ordinal \\
\hline
\end{tabular}




\begin{tabular}{|c|c|c|c|}
\hline & & & \\
\hline & & Conducting various workshops & Duration/ordinal \\
\hline & & Foreign language learning & Duration/ordinal \\
\hline & & Quantity of learned foreign & Quantity/ordinal \\
\hline & & languages & \\
\hline & & $\begin{array}{l}\text { Highest level of learned foreign } \\
\text { languages }\end{array}$ & Quality/ordinal \\
\hline & & Foreign language teaching & Duration/ordinal \\
\hline & & $\begin{array}{l}\text { Highest level of taught foreign } \\
\text { languages }\end{array}$ & Quality/ordinal \\
\hline & & Going to the theatre & $\begin{array}{l}\text { Frequency/ } \\
\text { ordinal }\end{array}$ \\
\hline & & Going to the opera & $\begin{array}{l}\text { Frequency/ } \\
\text { ordinal }\end{array}$ \\
\hline & & Going to the Philharmonic concert & $\begin{array}{l}\text { Frequency/ } \\
\text { ordinal }\end{array}$ \\
\hline & & Going to the museums & $\begin{array}{l}\text { Frequency/ } \\
\text { ordinal }\end{array}$ \\
\hline & & Going to the cinema & $\begin{array}{l}\text { Frequency/ } \\
\text { ordinal }\end{array}$ \\
\hline & & Going to art gallery & $\begin{array}{l}\text { Frequency/ } \\
\text { ordinal }\end{array}$ \\
\hline Education & Study & Max. and min. average term grade & Ordinal \\
\hline & & Max. and min. grade from test & Ordinal \\
\hline & & $\begin{array}{l}\text { Max. and min. grade from written } \\
\text { exams }\end{array}$ & Ordinal \\
\hline & & Max. and min. grades from essays & Ordinal \\
\hline & & $\begin{array}{l}\text { Max. and min. grades from oral } \\
\text { exams }\end{array}$ & Ordinal \\
\hline & Scientific & Science club membership & Duration/ordinal \\
\hline & & Active participation in conferences & Quantity/ordinal \\
\hline & & Passive participation in conferences & Quantity/ordinal \\
\hline & & Organisation of conferences & Quantity/ordinal \\
\hline & & Paper publishing & Quantity/ordinal \\
\hline
\end{tabular}




\section{RESULTS}

To verify if there were any significant differences in education outcomes and linguistic capital between female and male students, the T-Student test was conducted (for descriptive statistics see: Table 2). Results of the test indicate that there is a significant difference in scores regarding study results data block ( $\mathrm{t}=-1.31, \mathrm{p}=.032)$ and education outcomes meta-category $(\mathrm{t}=-2.08$, $\mathrm{p}=.039)$. Obtained results indicate that female students $(\mathrm{M}=0.09, \mathrm{SD}=0.962)$ have slightly higher study results scores than males $(\mathrm{M}=-0.21, \mathrm{SD}=1.064)$ and that female students $(\mathrm{M}=0.09, \mathrm{SD}=0.954)$ have higher education outcome scores than male students $(\mathrm{M}=-0.20, \mathrm{SD}=1.083)$ Results reveal no other significant gender differences regarding linguistic capital $(\mathrm{t}=-0.84, \mathrm{p}=.402, \mathrm{p}=0.121)$, scientific activity $(\mathrm{t}=-0.84, \mathrm{p}=0.401)$, writing activity $(\mathrm{t}=-0.08, \mathrm{p}=0.939)$, reading activity $(\mathrm{t}=-1.31, \mathrm{p}=0.190)$, and language experiences $(\mathrm{t}=-0.84, \mathrm{p}=0.401)$. Therefore, it is justified to state that female and male students do not differ significantly in terms of their linguistic capital, which proves that they had comparable experiences accumulated in previous stages of education. Simultaneously, they do differ in education outcomes, thus giving opportunity to state that similar linguistic capital may be used with different efficiency by different genders.

Table 2.

Descriptive statistics - Variable scores obtained by students.

\begin{tabular}{lllllllll}
\hline & Gender & $\mathrm{R}$ & $\mathrm{W}$ & $\mathrm{L}$ & $\mathrm{SR}$ & $\mathrm{SA}$ & $\mathrm{LC}$ & $\mathrm{EO}$ \\
\hline $\mathrm{N}$ & Male & 72 & 72 & 72 & 72 & 72 & 72 & 72 \\
& Female & 163 & 163 & 163 & 163 & 163 & 163 & 163 \\
Mean & Male & -0.129 & -0.00778 & -0.0828 & -0.211 & -0.0831 & -0.0828 & -0.203 \\
& Female & 0.0567 & 0.00307 & 0.0367 & 0.0934 & 0.0364 & 0.0363 & 0.0892 \\
Standard & Male & 1.08 & 0.976 & 0.934 & 1.06 & 1.03 & 0.985 & 1.08 \\
deviation & Female & 0.962 & 1.01 & 1.03 & 0.962 & 0.990 & 1.01 & 0.954 \\
Shapiro- & Male & 0.323 & $<.001$ & 0.176 & 0.706 & $<.001$ & 0.694 & 0.480 \\
Wilk p & Female & 0.409 & $<.001$ & 0.011 & 0.505 & $<.001$ & 0.165 & 0.173 \\
\hline
\end{tabular}

Note: R-reading Activity Score, W-Writing Activity Score, L-Language Experiences Score, SRStudy Results Score, SA-Scientific Activity Score, LC-Linguistic Capital Score, EO-Education Outcomes Score.

To verify such a statement, linear regression analysis was conducted. The constructed model included three variables: education outcomes meta-category score as dependant variable, linguistic capital meta-category score as covariate, and gender as moderating factor (coding: 1-female, 0 -male) and female as the reference value. Results of the linear regression reveal that the constructed model is significant $\left(F(2,232)=21.2, R^{2}=.15\right.$, $\mathrm{p}<.001)$. Regarding the used predictors, linguistic capital proves significant $(\mathrm{t}=6.11, \mathrm{p}=<.001)$ but gender $(\mathrm{t}=-1.89, \mathrm{p}=0.059)$ does not (for visualisation see: Figure 1). 


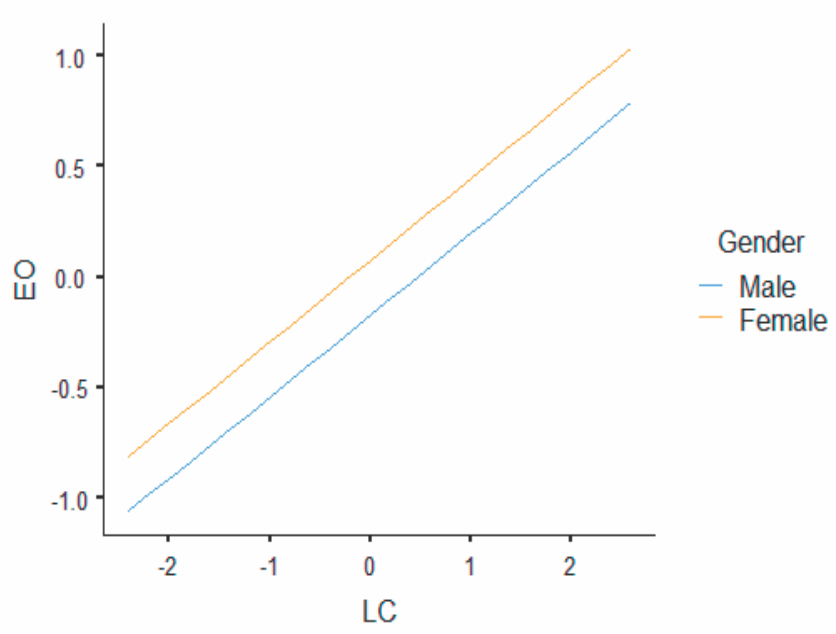

Figure 1. Estimated Marginal Means - Education Outcomes, Linguistic Capital, Gender.

Note: EO-Education Outcomes Score, LC-Linguistic Capital Score.

A similar analysis was conducted to test the impact of linguistic capital and gender on the study results and scientific activity of the students. Results of linear regression for study results indicate that the constructed model $(\mathrm{F}(2$, $232)=4.76, \mathrm{R}^{2}=.04, \mathrm{p}=.009$ ) provess significant, pointing out linguistic capital $(\mathrm{t}=2.18, \mathrm{p}=.030)$ and gender $(\mathrm{t}=-2.06, \mathrm{p}=.041)$ as significant predictors (Figure 2).

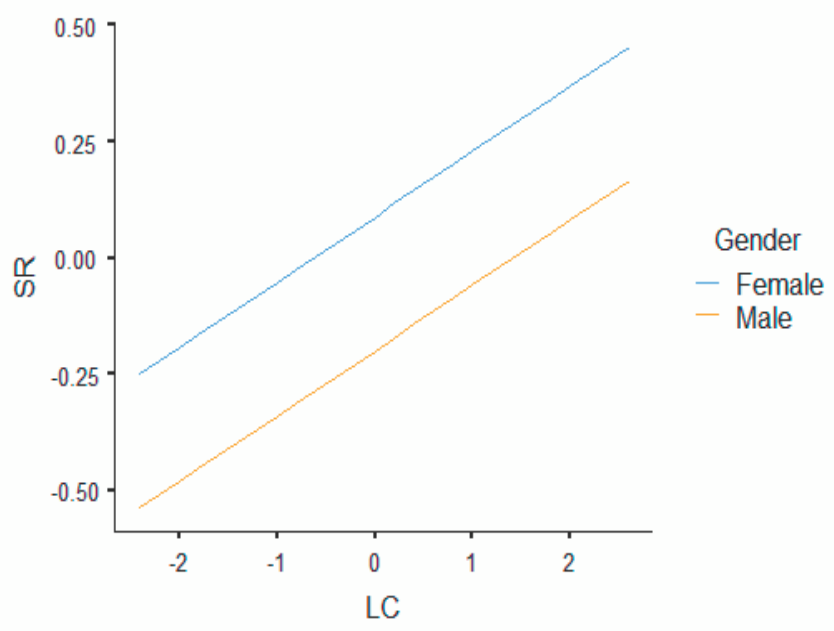

Figure 2. Estimated Marginal Means - Study Results, Linguistic Capital, Gender. Note: SR-Study Results Score, LC-Linguistic Capital Score. 
Results of linear regression for scientific activity indicate that the constructed model $\left(\mathrm{F}(2,232)=21.7, \mathrm{R}^{2}=.16, \mathrm{p}<.001\right)$ proves significant, pointing out (Figure 3 ) only linguistic capital as a significant predictor $(\mathrm{t}=6.52, \mathrm{p}<.001)$.

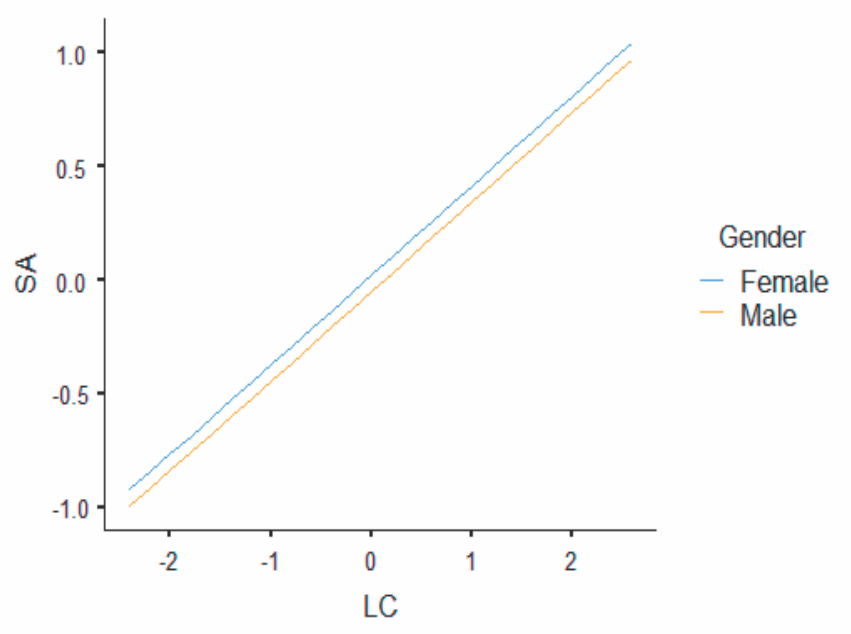

Figure 3. Estimated Marginal Means - Scientific Activity, Linguistic Capital, Gender.

Note: SA-Scientific Activity, LC-Linguistic Capital.

From the obtained data, it may be assumed that female students obtain significantly higher study results than males. Moreover, female students are equally capable of gaining scientific activity attainments as male students. Further exploration has been conducted to determine which blocks of linguistic capital are the best predictors of one's education outcomes when moderated by gender.

For that purpose, a further linear regression analysis was conducted. First models included education outcomes meta-category score as dependant variable and reading activity, writing activity and linguistic experiences as covariates. Gender was used as a moderating factor (coding: 1-female, 0-male). Results of the linear regression reveal that the created model $(F(4,230)=10.3$, $\left.\mathrm{R}^{2}=0.15, \mathrm{p}<.001\right)$ is significant, indicating reading activity $(\mathrm{t}=2.13, \mathrm{p}=.034)$ and language experiences $(t=4.26, p<.001)$ as significant predictors (Figure 4 ). Gender as a predictor was not significant $(\mathrm{p}=.081)$. 

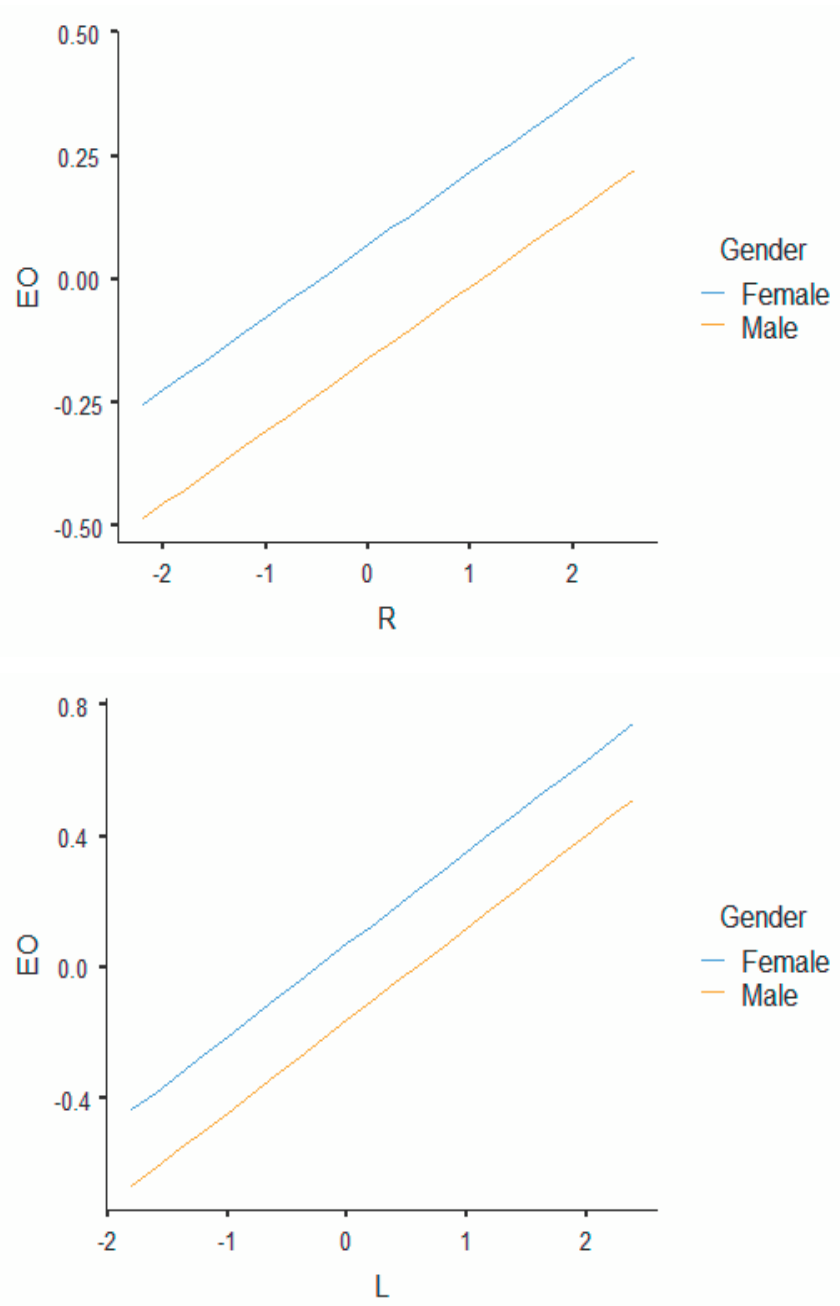

Figure 4. Estimated Marginal Means - Education Outcomes, Reading activity, Language Experiences, Gender.

Note: EO-Education Outcomes Score, R-Reading Activity Score, L-Language Experiences Score.

The second model included study results score as dependant variable and reading activity, writing activity and linguistic experiences as covariates. Gender was used as a moderating factor (coding: 1-female, 0-male). Results of the linear regression prove that the created model $\left(F(4,230)=2.58, R^{2}=0.04\right.$, $\mathrm{p}=.038)$ is significant, indicating language experiences $(\mathrm{t}=2.05, \mathrm{p}=.041)$ and gender $(\mathrm{t}=-2.03, \mathrm{p}=0.044)$ as significant predictors (Figure 5). 


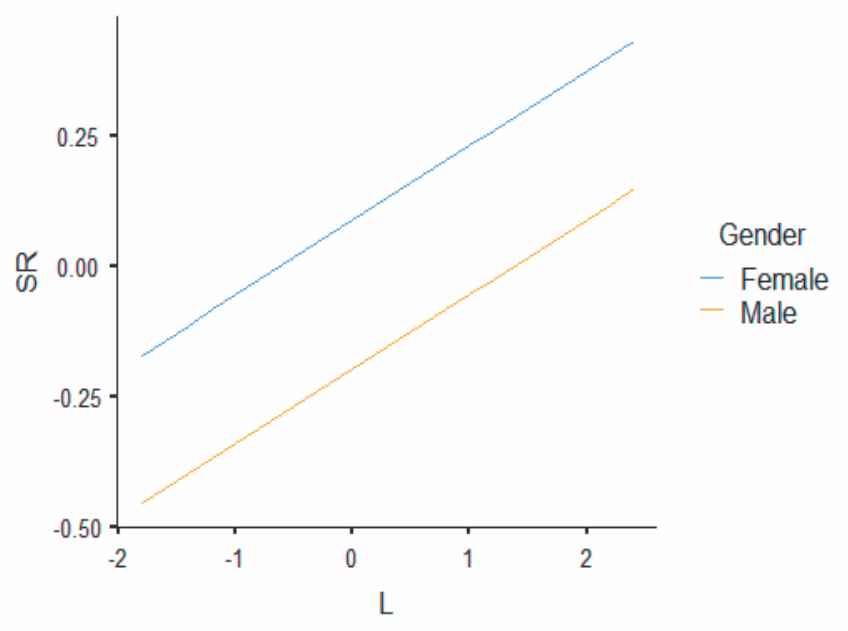

F0igure 5. Estimated Marginal Means - Study Results, Language Experiences, Gender.

Note: SR-Study Results Score, L-Language Experiences Score

The third model included scientific activity score as dependant variable and reading activity, writing activity and linguistic experiences as covariates. Gender was used as a moderating factor (coding: 1-female, 0-male). Results of the linear regression prove that created model $\left(\mathrm{F}(4,230)=10.3, \mathrm{R}^{2}=.15, \mathrm{p}<.001\right)$ is significant, indicating reading activity $(\mathrm{t}=2.92, \mathrm{p}=.004)$ and language experiences $(t=3.99, p<.001)$ as significant predictors (Figure 6$)$. In the tested model, gender proves to be an insignificant predictor $(\mathrm{p}=.703)$.

From the obtained data it is possible to state that gender is a significant moderator of linguistic capital in regard to the study results. The most important part of the linguistic capital which is fragile to gender differences are language experiences. Analysis indicates that female students obtain significantly higher scores than male students, and one of the factors that shape the education outcome and study results scores are language experiences. Results of the T-test indicate that there are no significant differences in language experiences area between female and male students. Therefore, it is possible to assume that female students are using their comparable language experiences more effectively than male students.

The most important findings point out that linguistic capital is an influential factor in predicting study results of students in regard to their gender. The posed question was which of individual components that are part of the linguistic capital and language experiences scores are the most influential predictors of study results when moderated by gender. 

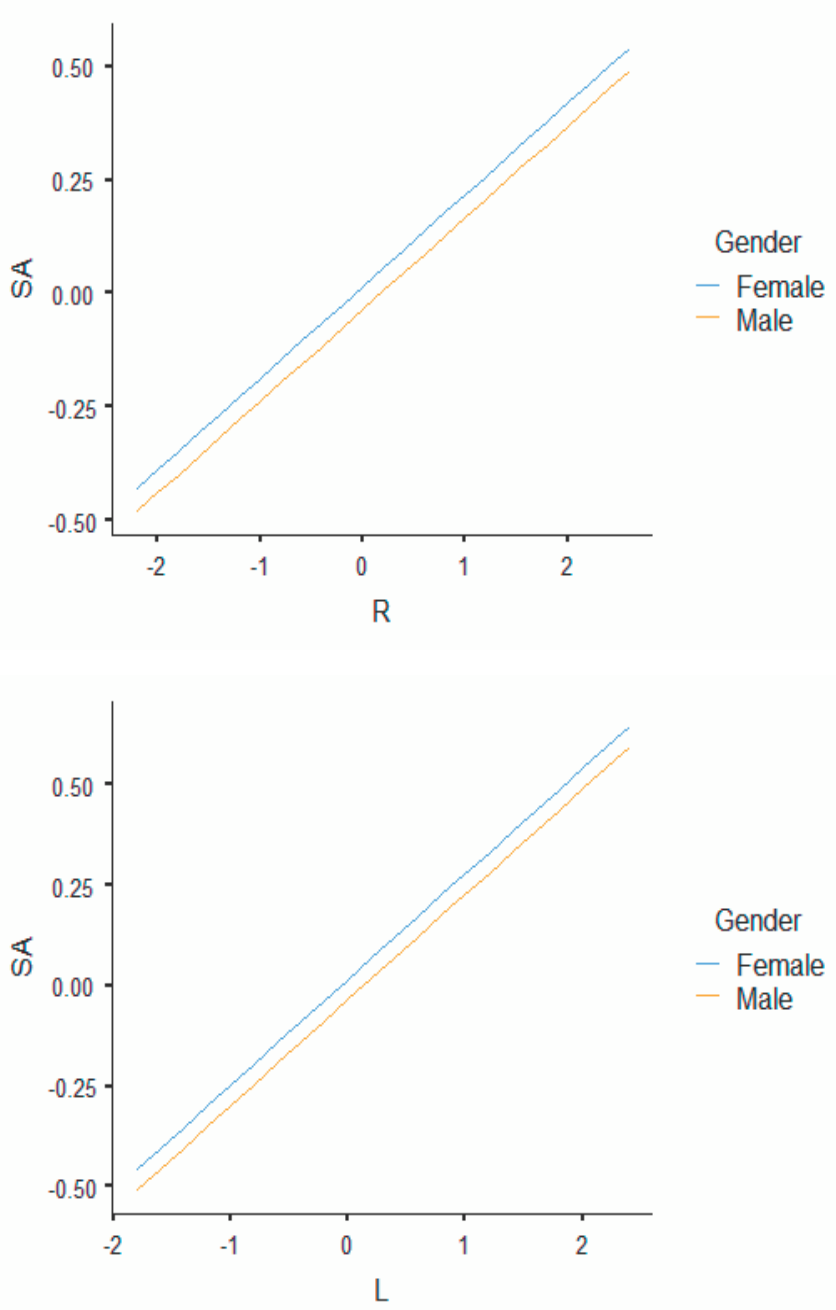

Figure 6. Estimated Marginal Means - Study Results, Language Experiences, Gender.

Note: SA-Scientific Activity, R-Reading Activity, L-Language Experiences.

Results of the linear regression regarding linguistic capital components in predicting education outcomes moderated by gender prove that the constructed model is significant $\left(F(38,196)=2.28, R^{2}=.31, p<.001\right)$. Individual component analysis indicate that watching audio/visual content $(\mathrm{t}=1.98, \mathrm{p}=.050)$, participation in literature contests $(\mathrm{t}=2.32, \mathrm{p}=.021)$, highest level of learned foreign language $(\mathrm{t}=2.45, \mathrm{p}=.015)$ and reading books $(\mathrm{t}=2.68, \mathrm{p}=.008)$ are significant predictors. In the tested model as an individual component, gender as a moderating factor is not significant $(p=.287)$. Linear regression results regarding linguistic capital 
components in predicting study results scores moderated by gender prove that the constructed model $\left(\mathrm{F}(38,196)=1.16, \mathrm{R}^{2}=.18, \mathrm{p}=.250\right)$ is not significant and gender as a predictor alike $(\mathrm{t}=1.06, \mathrm{p}=.292)$. Linear regression results regarding linguistic capital components in predicting scientific activity scores prove significant $\left(F(38,196)=2.47, R^{2}=.32, p<.001\right)$. Individual component analysis reveals that watching audio/visual content $(\mathrm{t}=2.63, \mathrm{p}=.009)$, participation in literature contests $(\mathrm{t}=2.94, \mathrm{p}=.004)$, going to art gallery $(\mathrm{t}=2.10, \mathrm{p}=.029)$, reading books $(\mathrm{t}=3.40$, $\mathrm{p}<.001)$, writing a diary $(\mathrm{t}=2.81, \mathrm{p}=.005)$ and writing poetry $(\mathrm{t}=1.98, \mathrm{p}=.049)$ are significant predictors. In the tested model as an individual component, gender as a moderating factor is not significant $(\mathrm{p}=.691)$.

Linear regression analysis proves that, although some elements of diagnosed linguistic capital are significant predictors of one's education outcomes and scientific activity, gender does not play the role of the important moderator of the latter. Such results are interesting because they imply that linguistic capital as a factor of education outcomes in gender perspective has great impact, but only as a broad cumulative experience.

\section{DISCUSSION}

Results of the study confirm earlier published results by Jacob (2002), Saunder et al. (2004), Dayioğlu, \& Türüt-Aşik (2007), Erten (2009), Wan Chik et al. (2012), Thiele et al. (2016), Tramonte, \& Willms (2010), Nishioka, \& Durrani (2019), proving higher female capabilities at higher education levels in comparison to males. It is interesting that general results confirm other results obtained from differing countries with significantly different cultural and social backgrounds such as Poland, Turkey, Malaysia, USA or South Africa and the common factors that connect different cultural backgrounds may be capitalistic culture and a free labour market, which creates visible structural differentiation and constitutes sharp social material inequalities in the given society. Such an explanation may be treated as an assumption regarding the forming of thelinguistic capital, which may be verified by future studies.

Diagnosed differences in this study give further proof for the positive confirmation of results obtained by Tramonte and Willms (2010), suggesting that females are generally better academic students, not only because they are, for example, more open to cooperation (Martinho, Albergaria-Almeida, \& Dias, 2015) but as this study shows, they use equally rich language experiences in amore efficient manner, which proves to be an advantage in Polish university education.

\section{CONCLUSIONS}

The conducted study shows that female students do not obtain general higher education outcomes than male students, although they do obtain generally higher study results than male students, which partially confirms the hypothesis stated earlier. Such results are possible for the female students to 
obtain due to the better usage of accumulated linguistic capital (which proves generally significant) and especially language experiences. Future studies should concentrate more on the individual impact of direct and indirect language experiences with the usage of a survey and experimental studies.

Due to the lack of any empirical data or lack of any arbitrary claims, it is assumed that all used indicators were equally important in the development of one's linguistic capital. Also, what may seem important are studies which will suggest what present and past experiences shape one's linguistic capital at given stages of education and human development. It would prove useful to create standardised diagnostic tools that would include universal features of linguistic capital to give the possibility for more unified comparative studies. Tools used in this study, although reliable and concerning many factors, may prove troublesometo replicate in the future, limiting the outcome significance of findings in this study. Further limitations are also the sample size $(n=235)$ and specific features of the compared groups of students (only social sciences), which seem to be homogenous in this matter. Inclusion of students from different fields, faculties and universities would prove valuable.

\section{ACKNOWLEDGEMENTS:}

This study was possible due to the financial support of University of Wrocław, in form of scientific scholarship gained by the author in a European Social Funds project entitled: Kształcenie wysoko kwalifikowanych specjalistów dla sfery publicznej w wymiarze transeuropejskim. Europejski Fundusz Społeczny. POKL.04.01.01-00-054/10.

\section{REFERENCES:}

[1] Almasi, M., Zhu, C., \& Machumu, H. (2018). Teaching, social, and cognitive presences and their relations to students' characteristics and academic performance in blended learning courses in a Tanzanian university. Afrika Focus, 31(1), 73-89. Retrieved from https://search. proquest.com/docview/2116054705?accountid=15143.

[2] Ayodele, T. O. (2019). Career choice of real estate students in Nigeria. The explaining influences in comparative perspective. Property Management, 37(1), 154-176. doi: 10.1108/ PM-02-2018-0013.

[3] Bekleyen, N. (2017). Understanding the academic procrastination attitude of language learners in Turkish universities. Educational Research and Reviews,12(3), 108-115. doi: https://doi. org/10.5897/ERR2016.3122.

[4] Bourdieu, P. (1973). Cultural reproduction and social reproduction. In: R. Brown (Ed.), Knowledge, education and cultural change (pp. 71-112). London: Tavistock.

[5] Bourdieu, P. (1986a). The forms of capital. In: J. Richardson (Ed.), Handbook of theory and research for the sociology of education (pp. 241-258). New York: Greenwood.

[6] Bourdieu, P. (1986b). The economics of linguistic exchanges. Social Sciences Information, 16(6), 645-668. doi: https:/ / doi.org/10.1177\%2F053901847701600601.

[7] Bourdieu, P. (1991). Language and symbolic power. Oxford, Cambridge: Polity Press.

[8] Bourdieu, P., \& Passeron, J. C. (1977). Reproduction in Education, Society and Culture (Theory, culture and society series). London: SAGE. 
[9] Davis, L., \& Reynolds, M. (2018). Gendered language and the educational gender gap. Economics Letters, 168, 46-48. doi: https://doi.org/10.1016/j.econlet.2018.04.006.

[10] Dayioğlu, M., \& Türüt-Aşik, S. (2007). Gender differences in academic performance in a large public university in Turkey. Higher Education, 53(2), 255-277. doi: https://doi.org/10.1007/ s10734-005-2464-6.

[11] Erten, İ. H. (2009). Gender differences in academic achievement among Turkish prospective teachers of English as a foreign language. European Journal of Teacher Education, 32(1), 75-91. doi: https://10.1080/02619760802586113.

[12] Ezeala, Ch. Ch., \& Siyanga, N. (2015). Analysis of the study skills of undergraduate pharmacy students of the University of Zambia School of Medicine. Journal of Educational Evaluation for Health Professions, 12, 12-46. doi: https://doi.org/10.3352/jeehp.2015.12.46.

[13] Fin, L. S., \& Ishak, Z. (2012). A Priori Model of Students' Academic Achievement: The Effect of Gender as Moderator. Procedia - Social and Behavioral Sciences, 65(3), 1092-1100. doi: https:/ / doi.org/10.1016/j.sbspro.2013.02.122.

[14] Gormley, S. (2015). Language and Gender. International Encyclopaedia of the Social \& Behavioral Sciences (Second Edition). doi: https://doi.org/10.1016/B978-0-08-097086-8.53055-4.

[15] Jacob, C. A. (2002). Where the boys aren't: non-cognitive skills, returns to school and the gender gap in higher education. Economics of Education Review, 21(6), 589-598. doi: https:// doi.org/10.1016/S0272-7757(01)00051-6.

[16] Kim, J., Kwon, Y., \& Cho, D. (2011). Investigating factors that influence social presence and learning outcomes in distance higher education. Computers and Education, 57(2), 1512-1520. doi: https://doi.org/10.1016/j.compedu.2011.02.005.

[17] Martinho, M., Albergaria-Almeida, P., \& Dias, J. T. (2015). Cooperation and Competitiveness in Higher Education Science: Does Gender Matter? Procedia - Social and Behavioral Sciences, 191(2), 554-558. doi: https://doi.org/10.1016/j.sbspro.2015.04.569.

[18] Mulac, A., Giles, H., Bradac, J. J., \& Palomares, N. A. (2013). The gender-linked language effect: an empirical test of a general process model. Language Sciences, 38, 22-31. doi: https:// doi.org/10.1016/j.langsci.2012.12.004.

[19] Nishioka, S., Durrani, N. (2019). Language and cultural reproduction in Malawi: Unpacking the relationship between linguistic capital and learning outcomes. International Journal of Education Research, 93, 1-12. doi: https:// doi.org/10.1016/j.ijer.2018.09.008.

[20] Núñez-Peñaab, M. I., Suárez-Pellicionic, M., \& Bono, R. (2016). Gender Differences in Test Anxiety and Their Impact on Higher Education Students' Academic Achievement. Procedia - Social and Behavioral Sciences, 228(20), 154-160. doi: https://doi.org/10.1016/j. sbspro.2016.07.023.

[21] López-Pérez, M. V., Pérez-López, C. M., Rodríguez-Ariza, L. (2011). Blended learning in higher education: Students' perceptions and their relation to outcomes. Computers \& Education, 56(3), 818-826. doi: https:// doi.org/10.1016/j.compedu.2010.10.023.

[22] Oladokun, T. T., \& Oladokun, S. O. (2017). Factors influencing real estate students' academic performance in an emerging economy: Gender and socioeconomic perspectives. Property Management, 35(5), 472-489. doi: https:// doi.org/10.1108/PM-08-2016-0041.

[23] Rafek, M. R., Ramli, N. H. Bt., Iksan, H. Bt., Harith, N. H., \& Che Abas, A. I. Bt. (2014). Gender and Language: Communication Apprehension in Second Language Learning. Procedia - Social and Behavioral Sciences, 123, 90-96. doi: https://doi.org/10.1016/j.sbspro.2014.01.1401.

[24] Raheem, B. O. A. (2017). The Influence of Gender on Secondary School Students' Academic Performance in South-West, Nigeria. Journal of Social Sciences, 31(1), 93-98. doi: https://doi. org/10.1080/09718923.2012.11893018.

[25] Saunder, J., Davis, L., Williams, T., Williams J. R. (2004). Gender Differences in Self-Perceptions and Academic Outcomes: A Study of African American High School Students. Journal of Youth and Adolescence, 33(1), 81-90. doi: https://doi.org/10.1023/ A:1027390531768.

[26] Schiebinger, L. (2000). Has Feminism Changed Science? Journal of Women in Culture and Society, 25(4), 1171-1175.

[27] Severiens, S. E., Ten Dam, G. T. M. (1994). Gender differences in learning styles: A narrative review and quantitative meta-analysis. Higher Education, 27(4), 487-501. doi: https:/ /doi. org/10.1007/BF01384906. 
[28] Subbaye, R., \& Vithal, R. (2017). Gender, teaching and academic promotions in higher education. Gender and Education, 29(7), 926-951. doi: http:/ /dx.doi.org/10.1080/09540253.2016.118 4237.

[29] Thiele, T., Pope, D., Singleton, A., \& Stanistreet, D. (2016). Role of students' context in predicting academic performance at a medical school: a retrospective cohort study, BMJ Open, 6:e010169. doi: https://doi.org/10.1136/bmjopen-2015-010169.

[30] Tramonte, L., Willms, D. J. (2010). Cultural capital and its effects on education outcomes. Economics of Education Review, 29(2), 200-213. doi: https://doi.org/10.1016/j. econedurev.2009.06.003

[31] Veldea, L., Tyrowicz, J., \& Siwinska, J. (2015). Language and (the estimates of) the gender wage gap. Economics Letters, 136, 165-170. doi: https:// doi.org/10.1016/j.econlet.2015.08.014.

[32] Wan Chik, W. Z., Salamonson, Y., Everett, B., Ramjan, L. M., Attwood, N., Weaver, R., Saad, Z., \& Davidson, P. M. (2012). Gender difference in academic performance of nursing students in a Malaysian university college. International Nursing Review, 59(3), 387-393. doi: 10.1111/j.1466-7657.2012.00989.x.7657.2012.00989.x 